\title{
ESTUDIOS
}

\section{La dimensión ética de la Administración Pública. Reflexiones a partir de la Constitución Española de 1978}

\section{Jaime Rodríguez-Arana'}

Palabras clave: Ética Pública, Administración Pública, Constitución Española, Derecho Constitucional, Derecho Administrativo.

Key words: Public Ethics, Public Administration, Spanish Constitution, Constitutional Law, Administrative Law.

La Constitución española de 1978, parafraseando a Zipellius, constituye el ambiente propio en el que deben explicarse, y entenderse, las principales categorías, instituciones y conceptos que componen el entero sistema del Derecho Público y la Ciencia Política. Otto Mayer hace muchos años sentenció, con su proverbial solemnidad: el Derecho Constitucional pasa, el Derecho Administrativo permanece. Y el célebre magistrado alemán Werner, refiriéndose a esta cuestión dejó escrito que el Derecho Administrativo es el Derecho Constitucional concretizado.

Evidentemente, no es este el momento ni el foro adecuado para trazar las relaciones existentes entre el Derecho Constitucional y el Derecho Administrativo. Sin embargo, ya que estamos en un seminario de especialistas en ética, es menester, en mi opinión, recordar que nuestra Norma Fundamental, como fuente de las fuentes del Derecho reconoce todo un conjunto de parámetros, vectores, criterios o principios

${ }^{1}$ Catedrático de Derecho Administrativo de la Universidad de La Coruña. Presidente de la Sección Española del Instituto Internacional de Ciencias Administrativas 
de Derecho, expresiones todas ellas de los valores superiores del Ordenamiento jurídico establecidos en el artículo 9.3 de la propia Constitución.

\section{La Administración Pública en la Constitución Española de 1978}

La caracterización constitucional de la ética pública requiere, con carácter previo, que analicemos el contexto social y político del principal elemento configurador de la existencia de la Administración Pública como es el interés general. Esto es así por la sencilla razón de que el entendimiento de la ética como ciencia social supone el estudio de la conducta humana de acuerdo con los postulados de la recta razón, lo que aplicado al ámbito de la función pública en sentido amplio implica un esfuerzo de comprensión de lo que puede significar, desde este punto de vista, el interés general en un Estado social y democrático de Derecho como el español.

Es bien sabido que uno de los conceptos que más aparecen en la Constitución es precisamente el interés general. Es lógico que sea así puesto que, en esencia, en un modelo de Estado social y democrático de Derecho, el Derecho Administrativo, como ha señalado atinadamente mi colega el profesor González Navarro, es el Derecho del poder para la libertad. Esta feliz construcción doctrinal ayuda sobremanera a hacerse una idea del sentido que tiene la función constitucional de la Administración Pública tal y como, por ejemplo, aparece caracterizada en los artículos 9.2, 10.1 y 103 de la Constitución, sin contar todas las referencias que el capítulo III de la Carta Magna atribuye a los poderes públicos como promotores de objetivos constitucionales de naturaleza social.

Ciertamente, el artículo 9.2 es uno de los preceptos más comentados y glosados del texto constitucional en orden a determinar el sentido y funcionalidad de los poderes públicos. Algún sector de la doctrina ha llegado a sostener que en dicho artículo se construye una auténtica función promocional de los poderes públicos dirigida a promover y facilitar la libertad y la igualdad de los individuos y de los grupos en que se integran. De esta manera, además de imponer a dichos poderes públicos la obligación de remover los obstáculos que impidan la efectividad de estos objetivos constitucionales, se afirma que, en efecto, la función esencial de los poderes públicos es una tarea abierta y comprometida con la libertad y la igualdad, lo que implica que toda la producción administrativa debe estar animada de esta relevante función. Evidentemente, desde la consideración de la ética 
pública como ciencia que estudia el comportamiento de las personas al servicio de los poderes públicos de acuerdo con el interés general, el artículo 9.2 cobra una especial relevancia.

Junto a este capital precepto constitucional nos encontramos, desde la perspectiva objetiva, con el artículo 10.1 que, como es sabido, dispone que "la dignidad de la persona, los derechos inviolables que le son inherentes, el libre desarrollo de la personalidad, el respeto a la ley y a los derechos de los demás son fundamento del orden político y de la paz social". Aquí se encuentra, en mi opinión, la determinación constitucional del alcance del interés general en el estado social y democrático de Derecho. Como ha señalado Garcia de Enterria en un trabajo de 1981 titulado La significación de las libertades públicas para el Derecho Administrativo, hoy el interés público reside en una labor de promoción de derechos de los ciudadanos superando una versión cerrada y casi patrimonial del interés público. Es más, si estamos de acuerdo en que la finalidad del Estado hoy es la garantía de los derechos de los ciudadanos desde la orientación que he denominado de la libertad solidaria, entonces podremos llamar la atención sobre la función que en esta materia corresponde a la Administración Pública en general y a sus agentes en particular. Que esto puede ser así se deduce sin dificultad de la cantidad y calidad de pronunciamientos de nuestro Tribunal Constitucional en los que, en sede de derechos fundamentales, queda bien claro que éstos constituyen uno de los objetivos del Estado social y democrático de Derecho y que, por tanto, la Administración cumple su dinamismo constitucional en la medida en que su actuación sigue estos postulados.

Por lo que se refiere al artículo 103.1 de la Constitución, debemos señalar, en este momento, que en este precepto se encuentra a mi juicio el ethos constitucional que la Norma Suprema atribuye a la Administración y a los poderes públicos en general. No es casual que el constituyente hubiera querido seleccionar entre las diferentes opciones posibles el término servicio para caracterizar la esencia de su función. En efecto, según dispone el artículo 103.1 la Administración sirve con objetividad el interés general. Es decir la Administración Pública está al servicio de los intereses generales, que desde esta perspectiva se nos presentan como un concepto jurídico indeterminado que, como señalé antes, en un Estado social y democrático de Derecho aparecen vinculados a la realización efectiva de la libertad solidaria. Si la Administración Pública sirve los intereses generales como persona jurídica, los agentes o empleados singularmente considerados deben distinguirse también por el servicio en su trabajo profesional ordinario de gestión pública, cualquiera que sea su posición en la maquinaria administrativa. Lógicamente, es diferente, en este sentido, la posición que pueda tener quien opera potestades 
públicas discrecionales que quien realiza tareas administrativas materiales más o menos mecánicas. Aquí se encuentra, pues, una fuerte componente ética de la caracterización constitucional de la Administración Pública que va a permitir a los ciudadanos juzgar acerca de la temperatura ética del aparato administrativo en general y en particular.

El servicio ha de ser objetivo pues tras la victoria del principio de legalidad y el ocaso de una manera de entender antigua en virtud de la cual el capricho y el puro deseo de dominación eran la fuente del Derecho, hoy emergen una nueva forma de concebir el ejercicio del poder de cuño objetivo que, por obvias razones, quizás porque la condición humana sigue siendo la misma que hace dos milenios, requiere de temple, de moderación, de equilibrio y de sensibilidad social pues, de lo contrario, el poder aparece en clave de fuerza racionalizada en lugar de ser un instrumento para promover la justicia y el interés general.

Estas son algunas de las reflexiones iniciales que me parece que pueden ayudar a entender el sentido de la ética pública en un tiempo en que ciertamente el poder, el dinero y la notoriedad, como ya advirtieron los clásicos, conducen, cuando se pierde la perspectiva instrumental, a toda suerte de desaguisados y estropicios que tienen en la base la desnaturalización del poder, que en lugar de ser, como decía Santi Romano, una función de servicio a la colectividad, tantas veces se convierte en instrumento de dominación, de laminación o de exclusión, cuando no de fuente de enriquecimiento.

\section{El interés actual por la ética}

Podemos definir la ética, en términos generales, como ese conjunto de principios y normas morales que regulan las actividades humanas de acuerdo con la recta razón, de tal manera que es la primera entre todas las ciencias prácticas. Más que como una reglamentación, debe entenderse como la fuente de las cualidades, la disposición al hábito moral y la adecuación personal al ideal humano. En el caso de la ética pública, la referencia ha de hacerse al interés general tal y como se ha comentado anteriormente.

Probablemente nunca a lo largo de toda la historia tantos han hablado tanto de ética. ¿2Por qué de repente un interés tan generalizado por las normas que deben regir íntimamente, si podemos hablar así, nuestro comportamiento? No pretendo dar una respuesta exhaustiva a esta cuestión, simplemente apuntar lo que a cualquiera de nosotros posiblemente le ha pasado por la cabeza con su sola mención. 
En el interés actual por la ética hay razones circunstanciales, como pueden ser los escándalos que nos sirve con mayor o menor intensidad y frecuencia la prensa diaria en todo el mundo. Hay razones políticas en este interés desusado, porque la ética se ha convertido en un valor de primer orden, o cuando menos (hay que admitirlo nos guste o no) como un cierto valor para el mercadeo político. Además, hay también situaciones de desconcierto, ante las nuevas posibilidades que ofrece la técnica, que exigen una respuesta clarificadora. Pero hay una razón de fondo que pienso que justifica plenamente el interés por las cuestiones éticas, e intentaré ahora referirme a ella con un poco de detenimiento.

En efecto, son incontestables los síntomas de que se están produciendo profundísimos y vertiginosos cambios en los modos de vida del planeta, hecho que se pone particularmente en evidencia en las sociedades avanzadas de Occidente, o en aquellas otras de dispares ámbitos geográficos que con mayor o menor éxito se han adaptado a las denominadas exigencias occidentales de vida. Estos cambios en los modos de convivencia son tan extensos, y se manifiestan con tal intensidad en las diversas áreas del entero existir (desde la producción a la comunicación, por ejemplo) que muy bien podemos estar asistiendo, como muchos pensadores han apuntado, a un cambio de civilización.

Todo el elenco (inacabable) de cambios en la estructura técnica de nuestra sociedad se traduce en transformaciones profundas, entre otras cosas, de nuestros modos de vida. Y con ellos se produce un derrumbamiento de los valores tradicionales, o más exactamente cabría decir, de los valores de la sociedad tradicional, entendiendo aquí tradicional en el sentido de una sociedad cerrada y rígidamente estructurada.

Se ha hablado mucho de la contraposición entre sociedades tradicionales y sociedades abiertas, y sin pretender entrar ahora en el pormenor de la cuestión, digamos que efectivamente es posible discernir en la sociedad que estamos configurando una serie de rasgos que la caracterizan en oposición con el modelo social que se va quedando atrás. La democracia, con todo lo que tiene de perfectible en los modos en que la articulamos, parece afortunadamente afianzarse universalmente como forma de organización de la vida política; al menos esa tendencia es clara. La participación en la vida pública por parte de todos los miembros de la sociedad se enriquece progresivamente, sobre todo en las sociedades avanzadas, posibilitándose la integración de los individuos en la vida social a través de un tejido asociativo cada vez más rico. El pluralismo alcanza todos los órdenes de la vida, extendiéndose a la cultura, caracterizándose así nuestras sociedades como sociedades multiculturales. La remodelación y desformalización de los roles socia- 
les más característicos de la sociedad tradicional contribuye, en algún sentido, a crear estructuras más equitativas y más respetuosas con la condición personal de todos los miembros de la sociedad. La ampliación del tiempo de vida, debido a las mejores condiciones de nuestra existencia y a los adelantos médicos y sociales, está provocando un incremento temporal de dos segmentos de la vida humana (la vejez y la juventud), con un inaceptable desplazamiento y marginación de sus integrantes.

Los valores de la sociedad tradicional (los de "nuestra" sociedad tradicional, habría que decir), repito, han quebrado, pero no lo han hecho los valores humanos, los valores que cimentan toda civilización y cultura posibles, y que de alguna manera son valores permanentes, de siempre. Por eso, la construcción de una civilización o de una nueva cultura no podrá hacerse sin volver sobre ellos. Sin embargo, no se trata de hacer una repetición mimética, sin más, no se trata de fotocopiar o de clonar. De lo que se trata es, en relación con los valores humanos, de pensarlos, de remozarlos, de renovarlos, de dotarlos de una nueva virtualidad que sólo la inventiva, la imaginación y la creatividad de esta criatura singular que es el hombre puede proporcionarles.

\section{Valores éticos para un cambio de civilización}

Ahora bien, si no podemos siquiera esbozar las nuevas relaciones, las nuevas estructuras que el hombre debe crear, sí podemos tal vez apuntar los valores desde los que ese cambio debe ser abordado, o algunos aspectos del sentido que debemos proponer a ese cambio.

En primer lugar la dignidad del hombre, de la persona, de cada vecino/a. Me gusta esta expresión "cada vecino", para subrayar la condición de realidad concreta del sujeto a que me estoy refiriendo. El hombre y los derechos del hombre, que se hacen reales en cada hombre, son para mí la clave del marco que queremos construir, y no nos exime esta aseveración de la necesidad de indagar y buscar una comprensión cada vez más cabal y completa de su significado. No me importaría ser tildado de reiterativo por esto, pero para mí la dignidad personal del hombre, el respeto que se le debe y las exigencias de desarrollo que conlleva constituyen la piedra angular de toda construcción civil y política y el referente seguro e ineludible de todo empeño de progreso humano y social.

Otro punto de apoyo esencial para abordar esta tarea civilizadora, que es una tarea ética, lo veo en la apertura a la realidad. La realidad es terca, la realidad 
es como es, y un auténtico explorador no debe dibujar edenes imaginarios en su cuaderno de campo, sino cartografiar del modo más fiel la orografía de los nuevos territorios. La apertura a la realidad significa también apertura a la experiencia. Apertura a la experiencia quiere decir aprender de la propia experiencia, y de la ajena. Quizás haya sido esta una de las lecciones más importantes que nos ha brindado la experiencia de la modernidad: descubrir la locura de creer en los sueños de la razón, que cuando se erige en soberana absoluta engendra monstruos devastadores. No hay ya sitio para los dogmas de la racionalidad absoluta. La aceptación de la complejidad de lo real, y muy particularmente del hombre, y la aceptación de nuestra limitación, nos conducirá a afirmar la caducidad y relatividad de todo lo humano (salvo, precisamente, el ser mismo personal del hombre) y a sustentar por lo tanto, junto a nuestra limitación, la necesidad permanente del esfuerzo y del progreso.

Pero lo que estoy haciendo (no se me malinterprete) es criticar una racionalidad que podríamos denominar absoluta, no la capacidad real de la razón para conocer, aunque sea de un modo todo lo limitado y parcial que se quiera. Es decir, pienso que es necesaria una reivindicación terminante de nuestra capacidad racional para conocer $y$, si vamos acompañados del acierto, para conocer progresivamente mejor la realidad.

Pues bien, para que nuestro conocimiento de las cosas progrese, para que superemos los límites que la modernidad ultraracionalista nos impuso, al tiempo que creía que nos hacía dueños totales de nuestro futuro, considero que debemos desarrollar lo que se ha llamado pensamiento compatible. Debemos desarrollar formas de pensamiento que nos permitan orillar las dificultades originadas por un pensamiento sometido a las disyuntivas permanentes a que nos condujo el racionalismo. El pensamiento compatible nos permite superar esas diferencias y apreciar que en la realidad se puede dar unido (y de hecho se da) lo que una mentalidad racional "matemática" (llamémosla así) nos exigía ver como opuestos. Estimo que es un imperativo ético hacer ese esfuerzo de comprensión. Posiblemente nos permitirá descubrir que realmente lo público no es opuesto y contradictorio con lo privado, sino compatible y mutuamente complementario, o que incluso vienen recíprocamente exigidos; que el desarrollo individual, personal, no es posible si no va acompañado por una acción eficaz a favor de los demás; que la actividad económica no será auténticamente rentable (en todo caso lo será sólo aparentemente) si al tiempo, y simultáneamente, no representa una acción efectiva de mejora social; que el corto plazo carece de significado auténtico si no se interpreta en el largo plazo; etc., etc. Que la norma no se opone a la libertad, sino que si es auténtica, justa, la potencia; que debe distinguirse la valoración moral de los 
comportamientos (que es una exigencia ética) del juicio moral de las personas, que es un abuso de nuestra condición racional... Discúlpenme, pero no me he resistido a hacer, aunque sea de pasada, una referencia a cuestiones tan fundamentales y tantas veces mal tratadas.

Pero tengo que mencionar, al menos, otro rasgo que debemos potenciar en nuestro acercamiento a las cosas: el pensamiento dinámico, que nos lleva a comprender que la realidad (y más que ninguna la social, la humana) es dinámica, cambiante, abierta, y no sólo evolutiva, preñada de libertad. Por eso debemos superar la tendencia a definir estáticamente, o con un equilibrio puramente mecánico, lo real, que no resistiría tal encorsetamiento sin sufrir una grave tergiversación. A esto venimos refiriéndonos, precisamente. Sobre la afirmación de su ser radical, el hombre ha de desarrollar las virtualidades que allí se encierran, tanto en lo que se refiere a su autodesarrollo personal como en lo relativo a la realización de su ser social. Pensar el hombre, la sociedad o la historia, a plazo fijo, con un punto final, como un proceso cuyo cierre vislumbramos, viene a ser negar el mismo ser del hombre. Quizás pueda afirmarse que ese ha sido el más grave error de la modernidad, o el de más graves y trágicas consecuencias.

Estas dos características del pensamiento y del conocimiento que, según me parece, debemos desarrollar y potenciar (el pensamiento compatible y dinámico), y las anteriores referencias a la dignidad del hombre y la apertura a lo real, fundamentan otro de los valores sobre los que debemos asentar nuestra acción: el diálogo. No me extenderé más en esta cuestión, únicamente apuntaré que el diálogo sólo es auténtico si se construye sobre una actitud profundamente ética. El diálogo es una acción propia no del hombre astuto, del negociador, del habilidoso, del que regatea en corto. El diálogo es propio del hombre bueno. Bueno no en el sentido de "bondadoso" (ya me entienden), en el de "torpe de buenas intenciones", ni siquiera me inclino a aceptar lo de "bueno, en el buen sentido de la palabra", como se definía el maestro Machado. El diálogo es propio del hombre bueno en el sentido fuerte de la palabra "bueno", en el sentido ético.

La participación, por último, es otra condición de acción de futuro, congruente con todo lo que venimos diciendo. Simplemente me limitaré a recordar aquella máxima kantiana de que el hombre no debe ser tomado nunca como medio, sino como fin. Y si lo que buscamos es un crecimiento en libertad, en humanidad, en definitiva, sólo podrá hacerse realidad ese objetivo, si cada uno se hace protagonista de sus acciones y de su desarrollo, y posibilita con su actuación que los demás también lo sean. Así entiendo la participación. 
La preocupación por la ética, por fortuna, no es hoy sólo una cuestión de moda llevada a cabo por simples razones de actualidad como pueden ser la corrupción política y financiera, las crisis económicas, la pérdida de legitimidad de las instituciones o la mutación de los sistemas de valores, sino que corresponde a un movimiento cultural e intelectual de fondo que parece presagiar el advenimiento de un nuevo ciclo en el desarrollo de la humanidad, en el que el factor ético será el generador del pensamiento, de la acción y de las relaciones de convivencia dentro y fuera de las organizaciones.

Es precisamente en el seno de estas organizaciones humanas donde se hace necesaria la recuperación de los valores éticos como referentes de su actuación. Las estructuras económicas y políticas son instrumentos al servicio del hombre, como también la Administración Pública debe promover los derechos fundamentales y hacer posible un ambiente de calidad y eficacia en el marco de la legalidad y del servicio público. Cuando se pierde de vista el carácter instrumental de las instituciones y los únicos aspectos que sobresalen son los mercantiles, entonces la lucha por los derechos fundamentales del hombre no puede menos que experimentar un claro retroceso.

\section{Nuevo enfoque de la Administración Pública como base para la ética}

Este renacimiento del interés por la ética se produjo concretamente en el mundo de los negocios y de la empresa privada hace dos décadas, teniendo como resultado el desarrollo, es cierto que todavía no muy logrado, de nuevas sensibilidades sociales de las empresas que transciende de lo puramente económico. La aplicación de esta reflexión ética a la Administración Pública es mucho más tardía, habiéndose fijado su nacimiento en 1978, fecha de publicación del primer libro sobre el tema (Ethics for bureaucrats de John Rohr). Es a esta última dimensión de la ética, la ética de la Administración Pública o ética pública, a la que voy a referirme a partir de este momento, tratando de proyectar sobre la organización administrativa los mismos valores éticos que (de acuerdo con el razonamiento que he venido desarrollando desarrollado) deben regenerarse para alcanzar el pregonado "cambio de civilización".

El paso de los años ha ido cambiando numerosos aspectos que rodean el régimen y funcionamiento de la Administración Pública. Siguiendo al profesor Peters, podemos resumir en tres las modificaciones más importantes acontecidas en el ámbito 
de la propia Administración Pública: los cambios políticos, entre los que destaca la implantación generalizada de sistemas democráticos; los cambios económicos, principalmente la austeridad en el gasto público impuesta por la crisis fiscal del Estado Social; y los cambios en la forma de gestión del sector público, mediante la importación de técnicas desde el "management" privado y la devolución de actividades hasta ahora públicas a la sociedad civil. A éstos deben añadirse los cambios tecnológicos que han revolucionado los instrumentos de gestión. Todos estos cambios han influido sobre el funcionamiento de la Administración y sobre el comportamiento de los propios funcionarios.

La Administración Pública del Estado social y democrático de Derecho es una organización que debe distinguirse por los principios de legalidad, de eficacia y de servicio. Legalidad porque el procedimiento administrativo no es otra cosa que un camino pensado para salvaguardar los derechos e intereses legítimos de los ciudadanos. Eficacia porque hoy es perfectamente exigible a la organización administrativa que ofrezca productos y servicios públicos de calidad. Y servicio, sobre todo, porque no se puede olvidar que la justificación de la existencia de la Administración se encuentra en el servicio a los intereses colectivos, en el servicio del bien común. Por eso, me atrevería a decir que una de las asignaturas pendientes de la Administración Pública de nuestro tiempo es la recuperación de la idea de servicio y, eso sí, la necesaria profesionalización de la Administración Pública que, en cualquier caso, ha de estar, no sólo abierta a la sociedad, sino pendiente ante las demandas colectivas para ofrecer servicios públicos de calidad.

Estas circunstancias, entre otras muchas, exigen un cambio sustancial en la concepción y actuación de la Administración Pública. Los programas de reforma y modernización de la Administración Pública deben tener como objetivo recuperar esta concepción instrumental de la Administración. Para ello, deben incidir sobre varios elementos claves, como son la introducción de criterios de competencia en la Administración, la desburocratización y simplificación de los procedimientos, la motivación del personal, así como la reducción del gasto público y su gestión de acuerdo con criterios de eficacia y eficiencia, en un marco en el que la Administración Pública contribuya decididamente a una constante humanización de la realidad.

Ahora bien, no se trata sólo de poner en marcha una reforma administrativa que camine única y exclusivamente hacia principios de eficacia y servicio. Se trata de algo más profundo: hacer posible que la calidad y la transparencia sean propiedades connaturales en la actuación de la Administración y de todos sus agentes. 
Como pone de manifiesto Vargas Moniz, la idea de la Administración Pública ligada a manifestaciones unilaterales de poder y autoridad está en crisis. El modelo tradicional constituido por una estructura jerarquizada y burocratizada, fuertemente ligada al poder político, indiferente a la realidad social y a los intereses de las personas, empeñada en preservar una peculiar y estática idea de independencia y de imparcialidad, colocándose al abrigo de intereses y presiones, y preocupada con sus secretos a fin de mantener y cultivar el distanciamiento de los ciudadanos, viene cediendo progresivamente el paso a una Administración Pública con otra filosofía y otro comportamiento. Una Administración Pública que sea una verdadera "casa de cristal".

Pues bien, la Administración Pública debe ser transparente en su servicio a los ciudadanos, ciudadanos que son quienes justifican su existencia. Durante los últimos años, la transparencia administrativa ha suscitado un interés creciente y un amplio consenso. Por todo ello, hablar de transparencia es hablar de uno de los valores esenciales en que se asienta la reforma y modernización de la Administración Pública como caracterización de lo visible, accesible y comprensible.

El concepto de transparencia no es antitético con el de eficacia. Para buscar esa Administración transparente es necesario programar la actividad y, por tanto, tomar decididamente la vía de la racionalización de los procedimientos, que inevitablemente conduce a una mayor eficacia. Por ello, la transparencia debe ser una prioridad, no sólo en la relación ciudadano-Administración, sino también dentro de la Administración misma, si queremos mejorar el funcionamiento de la maquinaria administrativa en su totalidad y si queremos disponer de un aparato administrativo que funcione con criterios éticos.

Por tanto, vincular transparencia y eficacia es esencial para evitar que la reforma administrativa sea únicamente formal, y así poder realizar una economía efectiva de los recursos y una mejora de los servicios.

La transformación del concepto de súbdito en el de ciudadano no sólo implica ser titular de derechos e intereses frente al Estado (Estado de Derecho), sino también que el respeto a la legalidad pase por la salvaguarda de las posiciones legítimas de terceros, superando la unilateralidad como forma de ejercicio de poder y la dependencia y sujeción como situaciones perennes de los interesados. Supone este proceso, en definitiva, la participación y la colaboración mutua de ciudadanos y Administración en un marco de transparencia, propio de un Estado social y democrático de Derecho. Es más, como ha reconocido solemnemente nuestro Tribunal Constitucional en 1984, hoy, los intereses públicos deben definirse en una 
acción combinada entre el Estado y los agentes sociales. En este punto, la Constitución Española es suficientemente clara, pues el artículo 105, ya establece los presupuestos necesarios para la participación de los ciudadanos en la actividad de la Administración Pública.

La identidad intereses administrativos/intereses de los ciudadanos, centrada en la promoción del bien general, exige que la Administración Pública sea un organismo transparente, abierto a la información, a la participación y al control democrático por parte de los ciudadanos.

Los mecanismos de transparencia exigen numerosas medidas organizativas y normativas. Entre ellas es fundamental la racionalización de los procedimientos administrativos, ya que, como pone de relieve Gennal, la transparencia no es un resultado que se obtenga sin haber cumplido antes la condición previa fundamental: procedimientos claros, documentados y difundidos entre todos los operadores internos y externos.

\section{5. Ética del funcionario público}

Pero más importante que las formulaciones normativas es la transformación de la mentalidad y de los comportamientos del personal al servicio de las Administraciones Públicas, capaz de hacer suyas estas importantes transformaciones, dando contenido concreto en la práctica a las medidas de reforma que se pretenden. Para ello es fundamental el comportamiento ético de los funcionarios. Es fundamental la ética pública. La ética pública es necesaria para reforzar las condiciones de credibilidad en la propia Administración Pública y en sus agentes, algo sustancial a la transparencia administrativa que ahora analizamos. Es más, me atrevería a decir que las consideraciones éticas en la función pública tienen una importancia creciente pues no se puede olvidar que el oficio público supone una tarea de servicio a los demás.

La ética pública, en una primera aproximación, estudia el comportamiento de los funcionarios en orden a la finalidad del servicio público que les es inherente. Es la ciencia que trata de la moralidad de los actos humanos en cuanto realizados por funcionarios públicos.

La ética pública es, como la ética en si misma, una ciencia práctica. Es ciencia porque el estudio de la ética para la Administración Pública incluye principios 
generales y universales sobre la moralidad de los actos humanos realizados por el funcionario público o del gestor público. Y es práctica porque se ocupa fundamentalmente de la conducta libre del hombre que desempeña una función pública, proporcionándole las normas y criterios necesarios para actuar bien.

La idea de servicio a la colectividad, a la sociedad, en definitiva, a los demás, es el eje central de la ética pública, como lo es la conservación del bien común. Esta idea de servicio al público es el fundamento constitucional de la Administración y debe conectarse con una Administración Pública que presta servicios de calidad y que promueve el ejercicio de los derechos fundamentales de los ciudadanos. Una Administración que se mueva en esta doble perspectiva, debe ser una Administración compuesta por personas convencidas de que la calidad de los servicios que se ofertan tiene mucho que ver con el trabajo bien terminado y de que es necesario encontrar -cuando así sea menester- los intereses legítimos de los ciudadanos en los múltiples expedientes que hay que resolver. Contribuir a la Administración moderna que demanda el Estado social y democrático significa, en última instancia, asumir el protagonismo de sentirse responsables, en función de la posición que se ocupe en el engranaje administrativo, de sacar adelante los intereses colectivos.

En un Estado social y democrático de Derecho, la Administración ya no es dueña del interés público sino que está llamada a articular una adecuada intercomunicación con los agentes sociales para definir las políticas públicas. Desde esta perspectiva puede entenderse mejor la función promocional de los poderes públicos, cuya misión es crear un clima en el que los ciudadanos puedan ejercer sus derechos fundamentales y puedan colaborar con la propia Administración en la gestión de los intereses públicos. En este contexto, pienso que estaremos más cerca de un aparato público que oferte servicios de calidad y que promocione los derechos fundamentales de los ciudadanos.

La ética pública se mueve en la frontera con la ley y el Derecho. La ética, hace referencia a valores objetivos que trascienden a la persona y que hacen referencia al comportamiento de los individuos. Es más, la ética supone la existencia de unos valores que van más allá del Derecho. Ahora bien, a los funcionarios y a los ciudadanos les conviene que estén tipificadas las faltas de servicio y que se distingan de las faltas personales porque, no todo en la función pública puede reducirse a derechos. Por eso es importante delimitar los ámbitos respectivos del Derecho y de la ética, aunque, eso sí, no pueden ser compartimentos estancos. Pero es también necesario recordar que en el mundo del Derecho existen toda una serie de principios entre los que los derechos fundamentales no son los menos 
importantes, que han permitido, o deben permitir, que el Ordenamiento jurídico discurra siempre por una senda de profundo respeto al hombre.

El Derecho es insuficiente para cubrir toda la actuación del funcionario y para remediar los perjuicios de lo que no es conforme a los cánones del buen gobierno, sobre todo en un contexto de creciente complejidad en el que la eficacia debe estar integrada en la legalidad y en los valores del servicio público.

De ahí la cada vez más evidente necesidad de una ética pública que debe configurarse como una "ética de máximos", fundada en principios o declaraciones universales que deben servir de guía para la reflexión, la comprensión moral y la actuación pública, en contraposición a una "ética de mínimos" basada en la mera formulación negativa de lo que no se puede hacer.

\section{Los principios de la ética de la función pública}

Los principios éticos para la acción administrativa no deben ser contemplados como restricciones para la actividad pública. No. Deben ser interpretados como garantías para una mejor gestión pública y como una oportunidad importante para que los ciudadanos sean más conscientes de que la Administración es una función de servicio y que únicamente busca la satisfacción de los intereses colectivos.

En este sentido, los principios de ética pública deben ser positivos y capaces de atraer al servicio público a personas con vocación para gestionar lo colectivo. Han sido muchos los estudiosos que han tratado de sintetizar los principios esenciales de la ética pública. La que a continuación reproduzco es una más de estas listas (en este caso un decálogo), cuyos principios pertenecen al sentido común y traen su causa de las exigencias del servicio público.

En primer lugar, los procesos selectivos para el ingreso en la función pública deben estar anclados en el principio del mérito y la capacidad. Y no sólo el ingreso sino la carrera administrativa.

En segundo lugar, la formación continuada que se debe proporcionar a los funcionarios públicos ha de ir dirigida, entre otras cosas, a transmitir la idea de que el trabajo al servicio del sector público debe realizarse con perfección. Sobre todo porque se trata de labores realizadas en beneficio de "otros". 
En tercer lugar, la llamada gestión de personal y las relaciones humanas en la Administración Pública deben estar presididas por el buen tono y una educación esmerada. El clima y el ambiente laboral han de ser positivos y los funcionarios deben esforzarse por vivir cotidianamente ese espíritu de servicio a la colectividad que justifica la propia existencia de la Administración Pública.

En cuarto lugar, la actitud de servicio y de interés hacia lo colectivo debe ser el elemento más importante de esta cultura administrativa. La mentalidad y el talante de servicio, en mi opinión, se encuentran en la raíz de todas las consideraciones sobre la ética pública y explica, por si mismo, la importancia del trabajo administrativo.

En quinto lugar, debe destacarse que constituye un importante valor deontológico potenciar el sano orgullo que provoca la identificación del funcionario con los fines del organismo público en el que trabaja. Se trata de la lealtad institucional, que constituye un elemento capital y una obligación central de una gestión pública que aspira al mantenimiento de comportamientos éticos.

En sexto lugar, conviene señalar que la formación en ética pública debe ser un ingrediente imprescindible en los Planes de Formación para funcionarios públicos. Además, deben buscarse fórmulas educativas que hagan posible que esta disciplina se imparta en los programas docentes previos al acceso a la función pública. $Y$, por supuesto, debe estar presente en la formación continua del funcionario. En la enseñanza de la ética pública debe tenerse presente que los conocimientos teóricos de nada sirven si no calan en la praxis del empleado público. Por eso, Lilla escribió no hace mucho tiempo que la vida moral del funcionario es mucho más que enfrentarse con supuestos delicados, se trata de adquirir un conjunto de hábitos operativos que le caractericen como un auténtico servidor público, como un gestor de intereses colectivos que busca el bien general en la sociedad.

En séptimo lugar, conviene resaltar que el comportamiento ético debe llevar al funcionario público a la búsqueda de las fórmulas más eficientes y económicas para llevar a cabo su tarea.

En octavo lugar, la actuación pública debe estar guiada por los principios de igualdad y no discriminación. Además la actuación conforme al interés público debe ser lo "normal" sin que sea moral recibir retribuciones distintas a la oficial que se reciben en el organismo en que se trabaja. 
En noveno lugar, el funcionario debe actuar siempre como servidor público y no debe transmitir información privilegiada o confidencial. El funcionario, como cualquier otro profesional, debe guardar el silencio de oficio.

En décimo lugary yúltimo lugar, el interés colectivo en el Estado Social y Democrático de Derecho se encuentra en facilitar a los ciudadanos un conjunto de condiciones que haga posible su perfeccionamiento integral y les permitan un ejercicio efectivo de todos sus derechos fundamentales. Por tanto, los funcionarios deben ser conscientes de esa función promocional de los poderes públicos y actuar en consecuencia.

En cualquier caso, y a pesar del decálogo de valores éticos que he enumerado, la formulación que debemos dar en estos tiempos a la ética no puede consistir tan sólo en enunciar valores deseables o atribuirles características ideales a los profesionales (bien sean éstos directivos o no), sino, por el contrario, se debe ser capaz de situar de manera práctica y efectiva, en los procesos de fijación de metas y objetivos, y desde allí impregnar toda la cultura de la organización para que sea compartida por todos los miembros de la misma y sirva de punto de referencia obligado para llevar adelante la gestión cotidiana.

\section{Conclusión: la responsabilidad del funcionario público}

Las Administraciones Públicas deberán fomentar modelos de conducta que integren los valores éticos del servicio público en la actuación profesional y en las relaciones de los empleados públicos con los ciudadanos, contemplando una serie de valores éticos que han de guiar la actuación profesional de los empleados públicos: voluntad de servicio al ciudadano, eficaz utilización de los medios públicos, ejercicio indelegable de la responsabilidad, lealtad a la organización, búsqueda de la objetividad e imparcialidad administrativa, perfeccionamiento técnico y profesional, etc.

La ética pública supone la enseñanza de un conjunto de conocimientos que deben convertirse en un hábito para el funcionario. No se trata de transmitir ideas tan interesantes como la lealtad institucional, el principio de igualdad, la transparencia, el uso racional de los recursos, la promoción de los derechos fundamentales de los ciudadanos, etc. Es imprescindible que la actividad del funcionario este presidida por un conjunto de valores humanos que están inseparablemente unidos a la idea del servicio y que, indudablemente, facilitan la sensibilidad ante lo público. Me 
refiero a virtudes tan importantes como la laboriosidad, la solidaridad, la magnanimidad o la modestia entre otras.

Pienso que si a alguien se puede exigir un plus especial de calidad humana es a los funcionarios y responsables públicos. Por una parte porque gozan de una serie de potestades que no tiene el sector privado y, por otra, porque la gestión de intereses colectivos es una de las actividades más trascendentales del horizonte profesional.

Realmente, el nivel de ejemplaridad y de altura ética que se exige al funcionario hace necesario que permanentemente las Escuelas de Administración Pública presten atención en sus programas docentes a estos temas. Junto a ello, que es muy conveniente, el propio funcionario debe hacer autocrítica sobre los motivos que le llevan a la actuación administrativa habitualmente. De esta manera, es más fácil tener presente los criterios éticos para la acción pública y así irá creciendo la sensibilidad colectiva de los empleados públicos.

Son en definitiva los propios empleados públicos los que deben asumir como propios los principios éticos, y aplicarlos a su actuación profesional y a sus relaciones con los ciudadanos. Ello sin duda modificaría la imagen peyorativa de la Administración y ayudaría a su rearme moral. En resumen, contribuiría decididamente a recuperar la tan difuminada idea de servicio público tanto en el ámbito privado como en el público.

\section{BIBLIOGRAFÍA}

E. García de Enterría (1981), "La significación de las libertades públicas en el derecho administrativo", Anuario de Derechos Humanos, Universidad Complutense de Madrid.

M. S. Gennal (1993), La transparencia administrativa en la ciudad de Florencia, Conferencia permanente de poderes locales y regionales del Consejo de Europa, Santiago de Compostela.

M. T. LILA (1981), "Ethos, ethics and public service", The public interest.

J. Rodríguez-Arana (2001), La dimensión ética, Madrid. 
J. Rodríguez-Arana (1993), Principios de ética pública, Madrid.

J. Rodríguez-Arana (2005), Ética, poder y Estado, Buenos Aires.

J. ROHR (1979), Ethics for bureaucrats, New York.

J. Vargas Moniz (1981), Transparencia da Administraçao pública, Centro de Estudios Autárquicos, $\mathrm{n}^{\circ} 1$, Coimbra. 